\title{
The notion of comfort, from word to concept
}

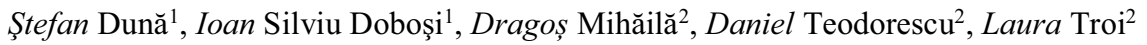 \\ ${ }^{1}$ SC Daro Proiect SRL, Timisoara, Romania \\ ${ }^{2}$ SC Dosetimpex SRL, Timisoara, Romania
}

\begin{abstract}
The notion of comfort emerged from a background of constraints caused by environmental, social, psychological, technological etc. factors, as a human attitude and endeavor to diminish these constraints and then to improve other elements that could ensure a different quality standard of life. In the last two decades, one can perceive an intensification of the efforts put into revealing the factors, together with their limitations, which contribute to achieving the state of comfort in various types of buildings considered isolated or in relation to others, in a rural or urban setting, and putting them into a standardized format that is to be taken into account. The increasing debates between specialists on the one hand and between specialists and occupants/users/residents on the other hand regarding the addition of new factors or the preeminence of their importance generates the re-contextualization of the notion of "comfort", whose elements are presented in this study. The last chapter proposes a different approach and understanding of the notion of comfort which can thus become a concept that finds its starting point in the way man is structured as a living being and takes
\end{abstract}

\section{Confort or comfort?}

\subsection{The problem of linguists}

In the debates about the current influences of English on the Romanian language over the last two decades, the idea of tolerance towards use has been transmitted. Generally, the necessary or luxury loans or returns to the spelling of origin are disturbing by excess, but not selfcondemning and each individual case is required to be carefully analyzed. There are also situation that are hardly tolerable by the linguists, which appear from the beginning as errors and imply not so much snobbery as ignorance and indifference to respecting the rules of language. One of the difficult situations tolerable is the graph of the word comfort. Linguits often brought into discussions the typical and radical substitution of one influence through another. The noun confort was borrowed in Romanian from French language. At present, in the Romanian cultural-scientific space, but also in the usual one, many people rebuild it in a graphic identical form to the equivalent noun in English. Some of the specialists say that the form with " $\boldsymbol{m}$ " does not bring any semantic difference and is most likely a simple mistake for those who are not sure about the correct Romanian writing, have taken the English language only because they have seen it more often lately. As such, the frequency of the error in the current use, in the Internet space, was verified with the help of the search engine Google and the results were unexpected. Comfort appeared as recorded, in Romanian texts, 10.700 times. By checking a sample reading, the specialists have established that the form is actually found in the most cases in English texts and especially as a commercial name: for cars, coffee filters, hotels etc. The high frequency of these appearances is determined by the familiarity that favors the translation of the form into Romanian. The Romanian texts in which comfort is attested belong to the most of the same stylistic categories: are advertisements, often translations or processing of messages written in English, but also appear in some situations which speaks of domestic products, especially buildings: "the hotel is recommended for tourists who want 4 star comforts "; "at Băile Tuşnad the state of confort is impeccable"; "sell apartment with 3 rooms, confort II". The same treatment is applied to the adjective confortabil (from the French term confortable), which becomes comfortabil after the English term comfortable. For instance: "the bedroom should be for everyone that place where can sleep comfortably".

As with other words, the word "comfort" has a going back and forth history to the European linguistic space. It

\footnotetext{
${ }^{1}$ SC Dosetimpex SRL Timișoara

2 SC Daro Proiect SRL, Timișoara
} 
comes from a verb from late Latin "confortare" (from con + fortis), starts in the Italian and French languages as "comfort" having the meaning of "moral strengthening, support, consolation". In Italian, this sense has been preserved so far in the form "conforto". The term was taken early in the English language where it also got insights into the material aspects of life that have returned to French and other Romance languages. In French, the sense "comoditate" (taken from English) has become dominant, while in Italian it is marginal, many people preferring for this meaning even the English but specialized loan "conforto" (with the meaning of consolation) and "comfort" with the sense of convenience. The specialists say that in Romanian language the word was certainly introduced from from French, proof of its unique meaning, defined in DEX as "all the material conditions that ensure a civilized, pleasant, comfortable and hygienic existence". And also that the current influence of English does not seem to produce semantic changes because where the word "comfort" is used, it does not attest to the sense of "support, courage, encouragement", that it currently has in English.

What makes the word "comfort" inappropiate is the suspicion of ignorance of the Romanian graphic norm. The problem of pronunciation does not necessarily refer to the difference between "confort" and "comfort" only when the pronouncements are intentionally market but on the writing mode. Normally, the phonetic context is one of neutralizing the difference between $\boldsymbol{n}$ and $\boldsymbol{m}$ before $f$ is simply pronounced a nasal. In neutralizing situations described by decades by linguitic specialistis, graphic errors are very common (obtiune/optiune, apsent/absent) and the norm itself oscillates over time (smeu/zmeu, sburător/zburător). In some languages the old phonetic evolutions have been accepted be the rues of the cult language, as is the case with the English language that accepted "comfort". In different languages different options may be made in respecting the tendencious of pronunciation or etymology, but specialists conclude that a conventional norm must exist and must be respected. Otherwise, it could be written in Romanian: comform, a comfesa, comferinţă, a comvieţui, a imvăţa, all justified by pronunciation. As such, in Romanian language, the graphic innovation of the word "comfort" is considered abusive. ( Source: România literară, "Păcatele limbii, confort", Rodica Zafiu)

\subsection{The meanings of the word "confort"}

Here are some definitions and forms of the word "confort" in several countries.

\section{Romania}

CONFORT n. All the material conditions that ensure a civilized, pleasant, comfortable and hygienic existence.from fr. . confort. Source: DEX '09 (2009)

CONFÓRT $n$. A set of conditions that constitute the convenience of material life. With all the comfort. $/<\mathrm{fr}$. confort Source: NODEX (2002)

CONFÓRT, conforturi, $n$. All the material conditions that make a lodging to be pleasant, hygienic and comfortable. Lodging with modern confort. . Source:
SCÎNTEIA, 1953, nr. 2744. Trăiesc în case nevoiașe de țară, fără confort și fără lumină. C. PETRESCU, Î. I 45.

CONFORT $\mathrm{n}$. which contributes to the good physical condition, to facilitating life. Source: Șăineanu, ed. a VIa (1929)

Confórt n., pl. urĭ (fr. confort, d. engl. confort, comes from fr. conforter, to strengthen, to give strength to).Convenience, construction and installation features at a home (water, bathroom, canal, electric light, garden) Source: Scriban (1939)

CONFÓRT n. convenience, quiet, rest. (the comfort of his life.)

France

CONFÓRT- Assistance matérielle en même temps que morale, ou simplement morale. Donner aide et confort. Dans cette affliction il ne reçut de confort de personne. On dit plutôt RÉCONFORT. Source: Dictionnaire de l'Académie française, huitième édition, 1932-1935

Étymol. et Hist. I. Ca 1100 "réconfort" (Roland, éd. Bédier, 1941); qualifié de "vieux" dep. Rich. 1680. II. 1815, 14 août "bien être matériel" (Chateaubriand, Correspondance générale [à Frisell] ds Mack. t. 1, p. 201 : le confort de la vie). I déverbal de conforter. Il empr. à l'angl. comfort attesté en 1814 (Wordsworth ds NED) au sens de "bien-être physique, matériel, aisance" et auparavant à celui de "ce qui donne la force"; "encouragement, consolation" (1225 Amer. R. 14 et 178, ibid.), sens où il est empr. à l'a. fr. sens I.

\section{England}

\section{COMFORT:}

1.- a state or situation in which you are relaxed and do not have any physically unpleasant feelings caused by pain, heat, cold;

2.- a state or feeling of being less worried, upset, frightened etc., during a time of trouble or emotional pain 3.- a person or thing that makes someone feel less worried, upset, frightened ;

4. - comforts [plural] - the things that make you more comfortable and that make your life easier and more pleasant Source: Encyclopædia Britannica.

Italy

In Italian, both forms are accepted and both are legitimate. Comfort is the most popular: it is a lon word from English and appears for the first time in written Italian towards the end of the nineteenth century, having the meaning of "all facilities offered to the occupants of a lodging or means of transport". Later, it appears in a more general sense of "convenience,facility" but also in the concrete sense of "everything that makes life easier and enjoyable in a certain environment". It is interesting to note that the notion of comfort, since 1920, has added to the existing meanings of the word conforto and the meanings of "convenience, facilitaty". But the use of the word conforto in this sense, nowadays, is considered literary and outdated. It must be said, however, that the etymology gives some justification, at least historically, to the legitimacy of the word confort, because the latter translates exactly the French word confort "conforto" from the 13th century. However, users do not take into account the etymological order, so that in today's Italian language comfort prevails - "convenience, facility". 


\subsection{The notion of "comfort" in Romanian norms and standards and / or adopted by Romania}

Because it is a complex notion with reference to several elements of interdependence of the external environment with the human being, in the Romanian literature is presented only to the notion of "thermal comfort" leaving many other segments of the comfort niche. Normally, in a future, the Romanian literature should be improved by a normative that defines the whole niche of "comfort" with all the elements and aspects arising from human necessity and not only.

In the present literature, "thermal comfort" is defined as the feeling of good physical condition resulting from the fact that heat exchange between the human body and the environment is achieved without overstressing the thermoregulatory system.

So, we find elements referring to the definition, parameterization, analysis and interpretation of "thermal comfort" in:

- I5 - 2010 - Norm for the design, execution and operation of ventilation and air-conditioning systems.

- SR EN ISO 7730 : 2006 - Moderate thermal environments - Analytical determination and interpretation of thermal comfort by calculation of PMV and PPD indices and specification of local thermal comfort criteria.

- SR EN 15251 : 2007 - Internal computing parameters of ambiance for designing and assessing the energy performance of buildings, which relate to indoor air quality, thermal comfort, lighting and acoustics.

- SR EN 13779 : 2005 - Ventilation of nonresidential buildings. Performance requirements for ventilation and air conditioning installations.

According to I5 - 2010, "thermal comfort" is determined by the following parameters:

- indoor air temperature,

- the average radiation temperature of the surfaces with which the human body changes heat by radiation,

- relative air humidity,

- indoor air speed,

- thermal insulation of clothing,

- the activity of the occupants that cause the heat to be released (metabolism).

SR EN 15251 : 2007 establishes the indoor ambiance categories presented in the following table:

\begin{tabular}{|l|l|}
\hline $\begin{array}{l}\text { Category } \\
\text { of } \\
\text { ambience }\end{array}$ & \multicolumn{1}{|c|}{$\begin{array}{c}\text { Characteristics and field of } \\
\text { application recommended }\end{array}$} \\
\hline I & $\begin{array}{l}\text { High level recommended for areas } \\
\text { occupied by highly sensitive and } \\
\text { fragile individuals with specific } \\
\text { requirements, such as sick, disabled, } \\
\text { small children, elderly }\end{array}$ \\
\hline II & $\begin{array}{l}\text { Normal level recommended for new or } \\
\text { renovated buildings }\end{array}$ \\
\hline III & $\begin{array}{l}\text { Moderately acceptable level, } \\
\text { recommended in existing buildings }\end{array}$ \\
\hline
\end{tabular}

\begin{tabular}{|l|l|}
\hline IV & $\begin{array}{l}\text { Level outside the above; recommended } \\
\text { to be accepted for limited periods of } \\
\text { time }\end{array}$ \\
\hline
\end{tabular}

"Thermal comfort" in a room is expressed by the value of PMV Predictable Medium Variable, which for each category of ambience in the table above must be included in the value range of SR EN 15251: 2007 according to the table:

\begin{tabular}{|c|l|l|}
\hline \multirow{2}{*}{$\begin{array}{l}\text { Category } \\
\text { of } \\
\text { ambience }\end{array}$} & \multicolumn{2}{|l|}{ The state of global thermal comfort } \\
\cline { 2 - 3 } & $\begin{array}{l}\text { The } \\
\text { percentage of } \\
\text { discontent } \\
\text { people } \\
\text { PPD } \\
\%\end{array}$ & $\begin{array}{l}\text { Predictable medium } \\
\text { vote } \\
\text { PMV }\end{array}$ \\
\hline I & $<6$ & $-0.2<$ PMV $<0.2$ \\
\hline II & $<10$ & $-0.5<$ PMV $<0.5$ \\
\hline III & $<15$ & $-0.7<$ PMV $<0.7$ \\
\hline IV & $>15$ & $\begin{array}{l}\text { PMV }<-0.7 \text { or PMV }> \\
0.7\end{array}$ \\
\hline & & \\
\hline & & \multicolumn{1}{|c|}{} \\
\hline
\end{tabular}

For the calculation of the PMV value and the percentage of PPD the method of Chapters 4 and 5 of SR EN ISO 7730: 2006 is applied. The required inputs sizes are determined according to the computing room characteristics (surfaces, thermal insulation), internal air calculation parameters and using as data:

- thermal resistance of the clothing according to Annex C of SR EN ISO7730: 2006;

- Heat released by persons (metabolism) according to Annex B of SR EN ISO 7730: 2006 or in Table 25 of SR EN 13779: 2005;

- in air-conditioned rooms where humidity is not regulated, a relative air humidity value of $50 \%$ is considered.

In certain situations determined by activity and clothing, related to some room destinations, considering the relative air humidity of $50 \%$ and low air velocities in the rooms, the calculation of the PMV values can be replaced by the calculation of the operative temperature. Operating temperature values for different destinations and categories of ambience are given in SR EN 15251: 2007 according to the table below. These operative temperature values can also be considered as computational values instead of the internal calculation temperature if using templates based on operative temperature.

\begin{tabular}{|l|c|c|}
\hline $\begin{array}{l}\text { Type of } \\
\text { building or } \\
\text { room }\end{array}$ & Category & \multicolumn{2}{|c|}{ Operative temperature } \\
\cline { 3 - 3 } & & $\begin{array}{l}\text { Minimum } \\
\text { for heating }\end{array}$ \\
\cline { 3 - 4 } & & $\begin{array}{l}\text { Maximum } \\
\text { for cooling }\end{array}$ \\
\hline
\end{tabular}




\begin{tabular}{|c|c|c|c|}
\hline & & $\begin{array}{l}\text { clothes } 1.0 \\
\text { clo }\end{array}$ & $\begin{array}{l}\text { clothes } 0.5 \\
\text { clo }\end{array}$ \\
\hline \multirow{3}{*}{$\begin{array}{l}\text { Lodging } \\
\text { buildings } \\
\text { (living rooms, } \\
\text { bedrooms) } \\
\text { sedentary } \\
\text { activity }-1,2 \mathrm{~m}\end{array}$} & $\mathrm{I}$ & 21.0 & 25.5 \\
\hline & II & 20.0 & 26.0 \\
\hline & III & 18.0 & 27.0 \\
\hline \multirow{3}{*}{$\begin{array}{l}\text { Lodging } \\
\text { buildings } \\
\text { (other rooms) }\end{array}$} & $\mathrm{I}$ & 18.0 & \\
\hline & II & 16.0 & \\
\hline & III & 14.0 & \\
\hline \multicolumn{4}{|l|}{$\begin{array}{l}\text { Standing up, } \\
\text { walking }-1,5 \\
\mathrm{~m}\end{array}$} \\
\hline \multirow[b]{3}{*}{$\begin{array}{l}\text { Individual or } \\
\text { landscape } \\
\text { offices, } \\
\text { meeting rooms, } \\
\text { auditors, } \\
\text { confectioners, } \\
\text { cafes, } \\
\text { restaurants, } \\
\text { classrooms } \\
\text { sedentary } \\
\text { activity }-1.2 \mathrm{~m}\end{array}$} & $\mathrm{I}$ & 21.0 & 25.5 \\
\hline & II & 20.0 & 26.0 \\
\hline & III & 19.0 & 27.0 \\
\hline \multirow{2}{*}{$\begin{array}{l}\text { Nurseries, } \\
\text { kindergartens }\end{array}$} & $\mathrm{I}$ & 19.0 & 24.5 \\
\hline & II & 17.5 & 25.5 \\
\hline \multicolumn{4}{|c|}{$\begin{array}{lr}\text { Standing up } \\
\text { walking }-1.4 \mathrm{~m}\end{array}$} \\
\hline Big shops & I & 17.5 & 24.0 \\
\hline Standing up & II & 16.0 & 25.0 \\
\hline walking $-1.6 \mathrm{~m}$ & III & 15.0 & 26.0 \\
\hline
\end{tabular}

Where there are certain comfort requirements, additional thermal comfort assessment criteria are considered, namely:

- radiation asymmetry;

- the vertical temperature gradient;

- air currents;

- floor temperature.

In order to assess the influence of these indoor conditions on comfort, the specialized literature refers to the calculation methods in SR EN ISO 7730: 2006 standard. It remains to be seen if in the near future the Romanian specialized literature will make an "upgrade" and alongside the term "thermal comfort" will appear other valences of human comfort

\section{Evolutionary adaptations of the concept of "confort" in foreign literature}

\subsection{Re-contextualizing the notion of "comfort"}

To what extent the speed of variation of local, zonal and global parameters that define the climate and the environment and the development or evolution of individual and collective needs materialized in isolated buildings or urban agglomerations as well as other artificial spaces that are desired by nature, new contexts for rethinking the notion of comfort?

In the last two decades, it has noticed that new notions are born in the notion of comfort, which include a vast regulatory framework with new conditions, new experiences and new types of system interactions between occupants / users / inhabitants and built systems as well as technologies that have become so innovative that they are also hardly known to users.

At present, the definition of comfort has become increasingly complex and varies greatly when the concept is viewed from the perspective of several disciplines, ranging from engineering and architecture to physiology and psychology, from social sciences to cultural anthropological ones.

When one of these disciplines analyzes or builds the idea of comfort from its perspective, it is found by the others that something has not been approached and the information is unsatisfactory. This gives rise to various understandings and paradigms of the notion of comfort which presuppose accepting the validity and complementary character of these different paradigms. It should be emphasized and understood that the notion of comfort has evolved over history, responding to various influences, such as social, technological, economic and cultural.

The processes that have passed are not static. Each of the additions or additions to the notion of comfort is based both on the knowledge and information bank held and historically formed, as well as on new needs that, once acknowledged, spring new aspirations and together with the first ones determine the evolutionary path. If today, through the voice and writing of specialists, the necessity of recontextualizing the notion of comfort is increasingly necessary, in the future it will become a more grounded concept, although it will always be evolutionary.

We are witnessing, over the past two decades, the ever obliviousness of the notion of comfort to a standardization process. Despite the acceptance and use of standards that derive in particular from the theory and from laboratory experiments, many elements that are considered empirical and difficult to measure or quantify through numerical parameters or values escape.

Scientists have recurred over time to various methods of assessing comfort and fitting it into standards. They began by measuring only the physical variables that influence an organism, such as the determination of heat exchange with the environment, and later they realized they need to supplement the standard picture with elements about thermal sensation and make assumptions about satisfaction or dissatisfaction. Awareness of the notion of discomfort rather than comfort can be more easily defined by two approaches to research approaches, possibilities, and policies: one that took into account more the lab results determined on selected subjects and one another that took into account "in situ" outbreaks on unselected subjects.

Taking into account the above, ASHRAE Standard 55 -"Thermal Environmental Conditions for Human Occupancy", whose purpose is to "specify those ambient 
combinations of the interior space and personal factors that will produce acceptable environmental thermal conditions for $80 \%$ or more of the occupants in a space", it felt the need for change. While "acceptability" is not precisely defined by the standard, within the research community of thermal comfort it is generally agreed the idea that "acceptable" is synonymous with "satisfaction" that "satisfaction" is indirectly associated with the thermal sensations of "warm", "neutral" and "little cool", and that the question of "thermal sensation" is most frequently encountered both in laboratory studies on thermal comfort and "in situ".

The ASHRAE 55 standard is currently based on the thermal balance model of the human body, which estimates that thermal sensation is exclusively influenced by environmental factors (temperature, thermal radiation, humidity and air speed) and personal factors (activity and clothing). An alternative theory of thermal perception that is intended to be complementary to the one used in the first model is the adaptive model, which states that other factors than those in fundamental physics and physiology play an important role in the formation of people's expectations and thermal preferences. Thermal sensations, satisfaction and acceptability are all influenced by the matching of one's expectations about the indoor climate in a certain context and what is real. While the thermal equilibrium model manages to take account of certain degrees of behavioral adaptation (eg changing clothing or adjusting local air speed), it fails to take into account the psychological dimension of adaptation, which could be particularly important in contexts where people's interactions with the environment (eg personal thermal control) or different thermal experiences can change their expectations and, therefore, thermal sensation and satisfaction.

Recently proposed revisions to the ASHRAE Standard 55 include a new adaptive comfort - ACS Adaptive Comfort Standard . It allows higher indoor temperatures for naturally ventilated buildings during the summer. ACS is based on the analysis of 21,000 sets of raw data compiled from "in-situ" studies carried out in 160 buildings, some air-conditioned and others naturally ventilated, located on four continents in various climatic zones. Conventionally, providing access to comfort is in fact the combination of building characteristics and physical, chemical and physiological occupant physics assurance systems, as well as the type and magnitude of control through a BMS available to operators (administrators who handle maintenance) in buildings and occupants / users / residents to meet the physiological, visual, acoustic and air quality requirements.

Figure 1 shows how access to comfort is provided in the conventional building design practice, focusing on mechanical and electrical systems and how decision makers operate independently of each other.

The sphere of action, emphasis and comfort requirements considered appropriate are represented by the standards applicable to certain types of buildings and the way in which they are used.

Characteristics that define comfort, such as the provision of parameters that determine the thermal, visual, acoustic, purity and freshness of air, etc., are presented mainly in the form of physiological comfort and limited psychological comfort elements of the occupants / users / inhabitants of a building. Thus, comfort standards serve as a guideline for design, and in service, the reference for authorities that should assess whether "acceptable" conditions for occupants / users / residents of the building. There are no such authorities in our country who could check whether a multifunctional building such as the mall is, for example, provided with fresh air

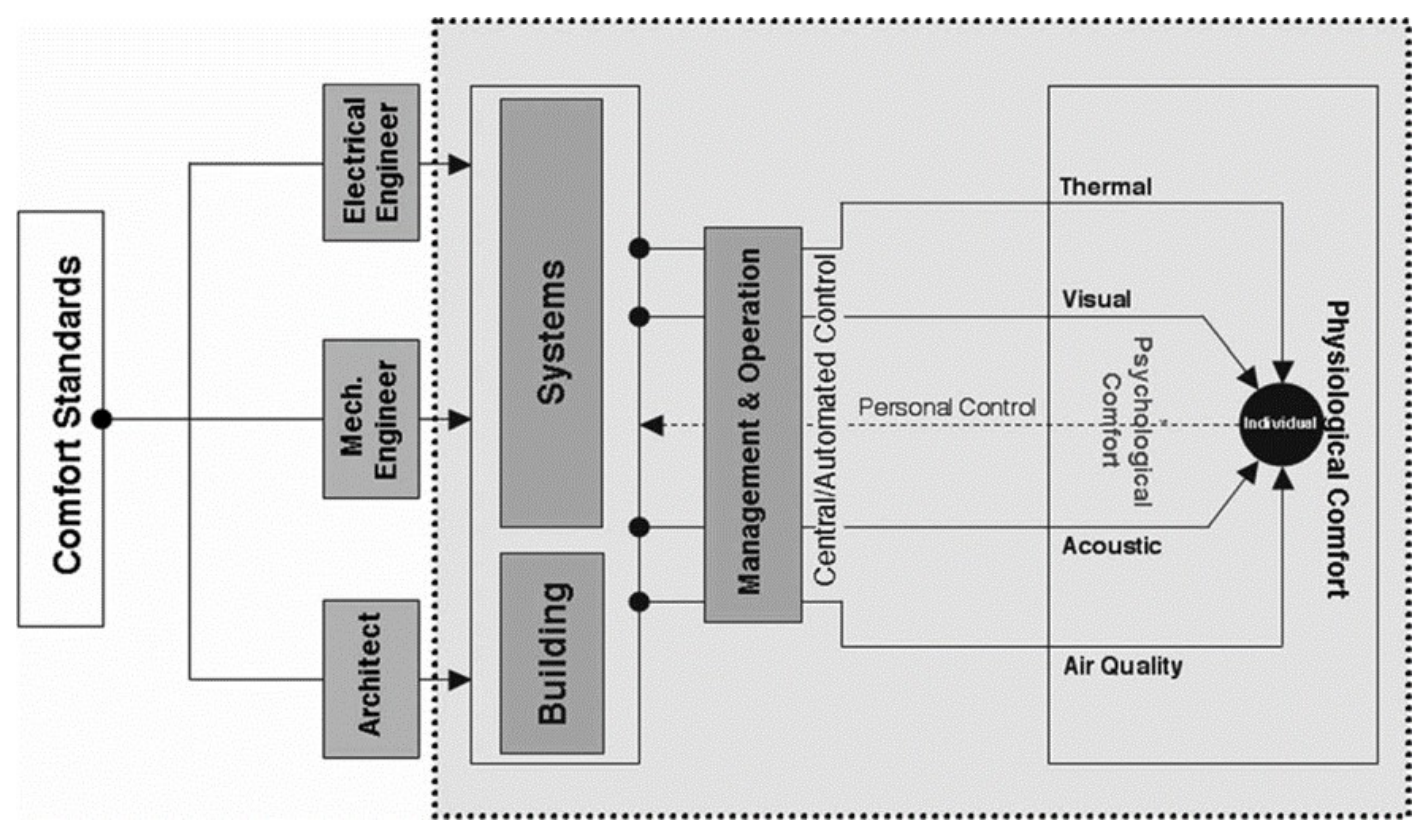

Fig.1. Source: Re-contextualizing the notion of comfort, Raymond J. Cole1, John Robinson, Zosia Brown and Meg O'Shea 
In addition, some of the essentials of comfort are often interpreted differently from the very beginning of the design phase, under the pressure of some of the customer's requirements on costs.

As Figure 1 shows, the physiological comfort and, to a very limited extent, the psychological comfort of the occupants / users / residents of the building or of that space are seen as a result of the design provisions with very few possibilities to obtain feedback from for shortterm changes.

The comfort approach, as is now being done and made conventional for the institutions dealing with it, takes too little account of the social dimensions and the manifestation of the occupants / users / inhabitants in this process. Although there is an attempt to reinforce the notion of comfort starting with the design, execution and management of the operation of the premises, they are more focused on the uniformity of characteristics and variables that define comfort, a situation that helps more predictability than a re-adaptation to various situations and / or resilience, that is the ability to recover its functions in short times. The fact that at the base of construction there are mainly a set of legislative and economic provisions, as well as technical norms that make their mark on them mostly without the involvement of the occupants / users / inhabitants, reduce the possibilities of their final purpose. Today it is considered that an intervention or an interactive relationship between the occupants / users / inhabitants with these spaces represents a great risk in terms of control and optimization of the system, increases the costs, makes it harder for those who handle the building management, users can intervene on the system without adequate training.

In recent years, however, differences have started in different areas to report comfort to occupants / users who have a daily or periodic presence less in that space and the inhabitants of a space such as a lodging where people can live in it even a lifetime, and where involvement in the regulation of comfort components can only be an action of the people who live there. Starting with a certain type of building, such as "zero energy buildings", "green buildings", "passive buildings", the notion of comfort is in the position of borrowing or taking over from what the specialists call "the instinctive connection between people and other living systems", "the inclination towards their natural value", meaning to take much more account of the biological and evolutionary history of man in its interdependence with other living systems.

There are also more and more specialists who say that it is necessary to achieve an integrated design of the comfort elements and to include complex teams of architects, engineers, designers, landscapeists, sociologists, psychologists, biologists who can reach a consensus in the realization of a multidisciplinary project.

Other specialists say that expanding regarding performance criteria of comfort by including conditions stemming from other human disciplines to take into account would be auspicious. There is a close interdependence between indoor and outdoor environmental conditions. Outside environmental variables are to some extent predictable and even cyclical over seasons over a year, but there is also a general change of the environment over several years, which is difficult to put into the equation.

However, it has curentlly come possible that the design level and existing technologies can set up a new comfort context that occupants / users / residents become active, adapts and works with system commands to adapt the system to their own comfort needs. This suggests a reorientation of the notion of comfort in which the goals and objectives of construction systems and occupants / users / inhabitants are as involved and equally satisfied.

Figure 2 illustrates the growing expansion of the notion of comfort. The points highlighted are in contrast to the current comfort concepts and the way in which comfort is defined in conventional practice as in Figure 1. In Figure 2, it is admitted that comfort research and access to it must go beyond the limits of physiological comfort, to address the psychological, behavioral and social (or collective) aspects of occupant / user / resident comfort.

It introduces a new system of buildings and habitat spaces that pursues interactive adaptive values, emphasizes these factors and has the flexibility to adapt to the changing needs of the entire system over a long period of time. These cultural, psychological, behavioral, social and contextual factors overlap and interact to determine the involvement and satisfaction experienced by a person over the prevailing environmental conditions. 


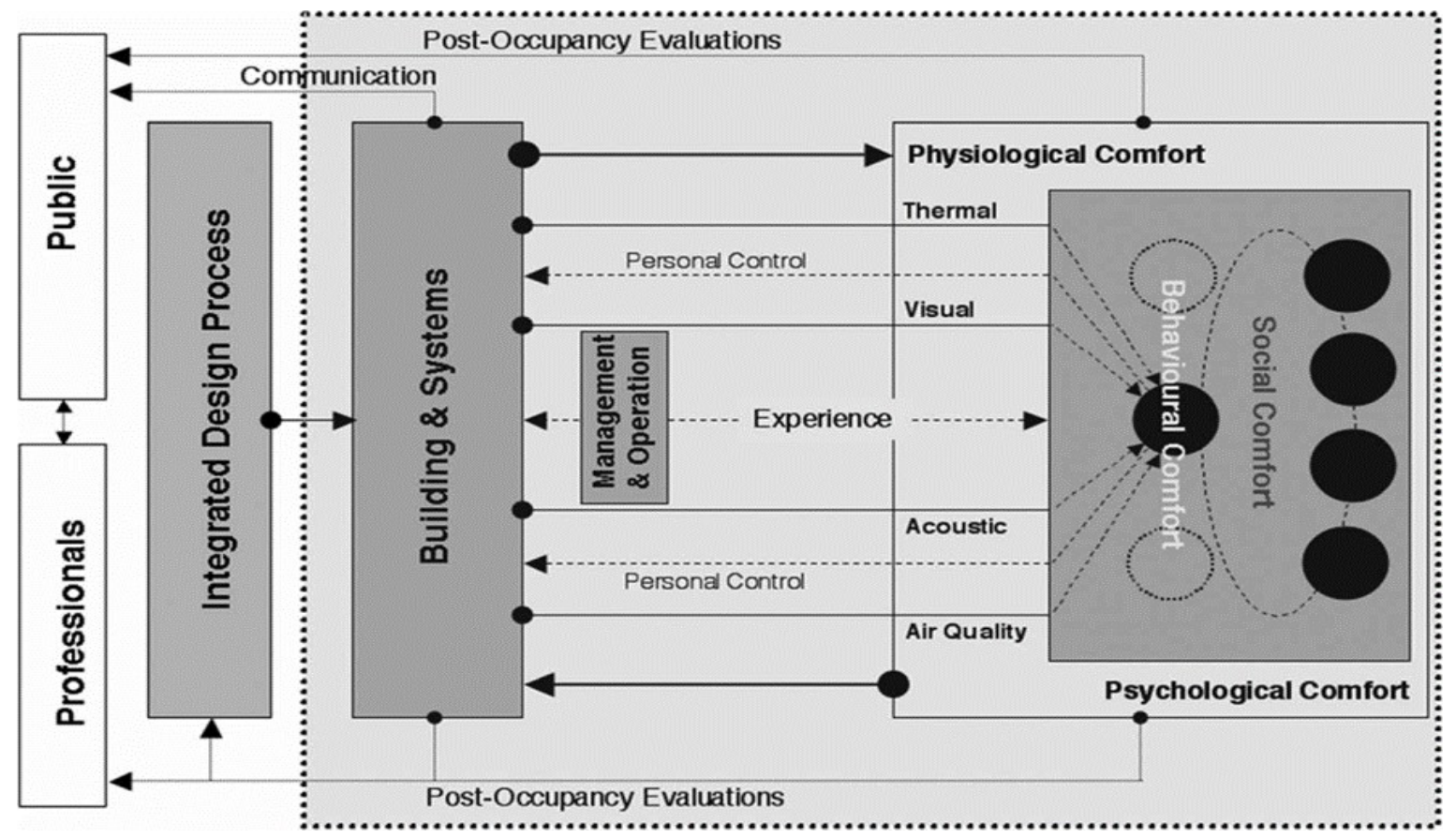

Fig.2 Source: Re-contextualizing the notion of comfort, Raymond J. Cole1, John Robinson, Zosia Brown and Meg O'Shea

\subsection{Another possible extension of the concept of "comfort"}

The schema of the two figures shows that the possibilities of the institutions involved in solving the conditions of comfort, beginning with the normative ones, then those of conception and the materialization and maintenance of the spaces occupied by occupants / users / inhabitants and which can benefit from some comfort only from the perspective of physiological and psychological needs. A holistic approach to both man's structures and the interdependence between these structures and the whole living environment that compose the environment would surprise new elements that bring new dimensions to the notion of comfort. Man and all living systems are not isolated on Earth, there is a permanent exchange of information and energy between them, often escaping the measurements of $\mathrm{AMCs}^{3}$ used by science and today's technology. Satisfaction in humans, but also to other living systems, is generally determined by the way, the time, the quantity and the quality in which they can provide in their own balance the information and energies necessary for the fundamental processes of life and evolution, to the fulfillment of their existential purpose. The nature of man, as he is built by the Creator, shows that the informational and energetic balance that gives him the degree of satisfaction or dissatisfaction of the man and provides him with food, breathing, physical biofields and sleep. Each of these areas overlaps their input, only partially. A man who has not slept for 3 days and nights can not fill in the balance what he needs only through food, regardless of its quantity and quality. Each of the four areas contributes not only to physical and psychical being, but also to other structures undetected by science, but to which the attitude of their existence exists, as one is the soul. If we leave this concept - that man has more structures, and analyze how he is created, we notice that physical structure or physical body has five senses organized so that each interacts with forms of organization of matter. For example, the tactile sense is generally related to a solid matter organization, the sense of taste with a form of liquid organization, the olfactory with the gaseous, the auditory with the sound waves and the visual with the light waves. The other bodies or structures of man, other than the physical one, also have "sense organs", which begin their investigation on a matter that is finer than the light wave investigated by the visual sense. So man has organs of sense and other structures than the physical body, by which he interacts, interacts and exchanges substance, information and energy with the other creations. This way to relate, as well as the exchange with the environment that is noticeable or unreceivable by the current technologies, determines its state of satisfaction and comfort. In a

\footnotetext{
${ }^{3}$ measuring and control equipment
} 
building with all possible facilities, there may be situations of dissatisfaction and even constraints for some people that diminish their own balance, which leads to the conclusion (valid for him) that there is something that does not give him comfort and even aggresses him. In a building made of non-homogeneous structures, such as concrete and metal, or placed in lands with a nonhomogeneous depth structure, a range of "constructive tensions" or "teluric" can occur, which sensory organs other than those five known by science, find them "aggressive" from the point of view of providing their own balance sheet and hence a discomfort that can not be removed for the time being through known technological solutions. Many studies have found that placing a building in a certain area can facilitate or diminish the occupants' natural activities. Also, a major influence on man and his activity has all kinds of "terrestrial and / or astral radiation" and can not be isolated today at the entrance to the boundaries of a building or a living space. And the examples go on. As such, taking into account the

\section{References}

1. I5-2010 - Normative for the design, execution and operation of ventilation and air-conditioning systems.

2. SR EN $15251: 2007$ - Internal computing parameters for designing and assessing the energy performance of buildings, which relate to indoor air quality, thermal comfort, lighting and acoustic.

3. SR EN 13779 : 2005 - Ventilation of non-residential buildings. Performance requirements for ventilation and air conditioning installations.

4. SR EN ISO 7730 : 2006 - Moderate thermal

Environments - Analytical determination and interpretation of thermal comfort by calculation of PMV above and which will be explained in more detail in another work, the notion of comfort becomes a concept that aims at creating and using all spiritual, rational, material, knowledge, social and educational possibilities materialized through constructive, technological, environmental and other elements, through which man assures himself and living systems the natural possibility to relate and to assure all the specific and necessary elements (substances, information, energies) that are detectable and taken over by all sensory organs of all the structures and bodies that define it as an entity, for its own balance sheet as the source of the fundamental processes of life and evolution, at the times and in the quantities and qualities required for the purpose for which it was created, without affecting other living systems. This attitude described above is inscribed by the Creator in the Human Matrix of Matter, only that he has to imply and convey it naturally

and PPD indices and specification of local thermal comfort criteria

\section{ASHARE - Adaptive Thermal Comfort Standard.}

6. Jenna Kamholz, Lisa Storer - Regional an Historic Standards of Comfort - University of Texas.

7. Richard J. DeDear- Thermal Comfort in Practice Indoor Air, Blackwell Munksgoard 2004.

8. Raymond J. Cole, Jhon Robinson, Zosica Brown, Meg O'Shea -Re-contextualzing the notion of Comfort University of British Columbia Vancouver. 